\title{
The effect of surgical approach in total hip replacement on outcomes: an analysis of 723,904 elective operations from the National Joint Registry for England, Wales, Northern Ireland and the Isle of Man
}

\author{
Ashley W. Blom,2, Linda P. Hunt', Gulraj S. Matharu" ${ }^{1 *}$, Michael R. Reed ${ }^{3}$ and Michael R. Whitehouse ${ }^{1,2}$
}

\begin{abstract}
Background: Total hip replacement (THR) is clinically and cost-effective. The surgical approach employed influences the outcome; however, there is little generalisable and robust evidence to guide practice.

Methods: A total of 723,904 primary THRs captured in the National Joint Registry, linked to hospital inpatient, mortality and patient-reported outcome measures (PROMs) data with up to 13.75 years follow-up, were analysed. There were seven surgical approach groups: conventional posterior, lateral, anterior and trans-trochanteric groups and minimally invasive posterior, lateral and anterior. Survival methods were used to compare revision rates and 90-day mortality. Groups were compared using Cox proportional hazards and Flexible Parametric Survival Modelling (FPM). Confounders included age at surgery, sex, risk group (indications additional to osteoarthritis), American Society of Anesthesiologists grade, THR fixation, thromboprophylaxis, anaesthetic, body mass index (BMI) and deprivation. PROMs were analysed with regression modelling or non-parametric methods.

Results: Unadjusted analysis showed a higher revision risk than the referent conventional posterior for the conventional lateral, minimally invasive lateral, minimally invasive anterior and trans-trochanteric groups. This persisted with all adjusted FPM and adjusted Cox models, except in the Cox model including BMI where the higher revision rate only persisted for the conventional lateral approach (hazard rate ratio (HRR) 1.12 [95\% Cl 1.06,1.17] $P<0.001$ ) and trans-trochanteric approaches (HRR $1.48[95 \% \mathrm{Cl} 1.14,1.91] P=0.003)$. PROMs demonstrated statistically, but not clinically, significant differences. Self-reported complications were more frequent with the conventional lateral approach, and the risk of 90-day mortality was higher (HRR 1.15 [95\%Cl 1.01-1.30] $P=0.029$ ).

\footnotetext{
* Correspondence: gulraj.matharu@bristol.ac.uk

'Musculoskeletal Research Unit, Translational Health Sciences, Bristol Medical School, 1st Floor Learning \& Research Building, Southmead Hospital, Bristol BS10 5NB, UK

Full list of author information is available at the end of the article
}

(c) The Author(s). 2020 Open Access This article is licensed under a Creative Commons Attribution 4.0 International License, which permits use, sharing, adaptation, distribution and reproduction in any medium or format, as long as you give appropriate credit to the original author(s) and the source, provide a link to the Creative Commons licence, and indicate if changes were made. The images or other third party material in this article are included in the article's Creative Commons licence, unless indicated otherwise in a credit line to the material. If material is not included in the article's Creative Commons licence and your intended use is not permitted by statutory regulation or exceeds the permitted use, you will need to obtain permission directly from the copyright holder. To view a copy of this licence, visit http://creativecommons.org/licenses/by/4.0/. The Creative Commons Public Domain Dedication waiver (http://creativecommons.org/publicdomain/zero/1.0/) applies to the data made available in this article, unless otherwise stated in a credit line to the data. 
(Continued from previous page)

Conclusions: Lateral approaches for THR are associated with worse outcomes, including more deaths and revisions, than the posterior approach. We recommend the posterior approach should be considered the current standard approach for THR. Large well-designed studies are needed to assess any potential benefits from using minimally invasive posterior approaches and the conventional anterior approach.

Keywords: Hip replacement, Surgical approach, Outcomes, Revisions surgery, Mortality

\section{Introduction}

Total hip replacement (THR) is a common operation with low revision rates [1], excellent patient-reported outcome measures (PROMs) [2] and low mortality [3]. Efforts to improve outcomes focus on specific factors, such as implants [4] and thromboprophylaxis [5]. Surgical approach is a relatively simple way to effect outcomes. Although attention has been given to surgical approach over the last decade (e.g. use of mini-incisions, and more recently the anterior approach) [6,7], there is a lack of well-designed studies comparing outcomes when using different hip approaches.

For THR, the hip can be approached anteriorly, laterally, posteriorly or by detaching the greater trochanter (transtrochanteric). Each approach can be performed through a limited (minimally invasive) incision/s, although this is extremely rare for the trans-trochanteric, leaving seven common approaches. The anterior approach is intermuscular, the lateral passes through the major hip abductors and the posterior through the short external rotators. The type and extent of soft tissue damage and bleeding caused by each approach differs and thus influences outcome [8-11].

Using data from the National Joint Registry (NJR) for England, Wales, Northern Ireland and the Isle of Man, we compared implant survivorship, PROMs and postoperative mortality between the seven common surgical approaches used for primary THR.

\section{Methods}

Our initial cohort comprised 890,681 linked THRs, performed between 1 April 2003 and 31 December 2016 [12]. We excluded 21,549 (2.4\%) where data was collected on version 1 of the minimum data set collection form (MDS v1) that combined the anterior and anterolateral approach. Of the remaining 869,132, we selected 800,555 where osteoarthritis (OA) was stated as an indication for surgery but, further, sequentially excluded any that reported, in addition to OA, fractured neck of femur (1074), fractured acetabulum (209) and previous arthrodesis or failed hemiarthroplasty (253), leaving 799, 019 for initial analysis (Fig. 1), with a maximum potential follow-up of 13.75 years.

Surgical approach was grouped as (i) posterior, (ii) lateral, anterolateral, Hardinge (an eponymous name for a variant of the lateral approach), (iii) anterior or other and (iv) trans-trochanteric (overriding the others). These groups were further subdivided according to whether or not minimally invasive surgery (defined as skin incision lengths of less than $10 \mathrm{~cm}$ ) was used, giving 8 potential subgroups. There was a secular increase in the use of the posterior approach (Additional file 1: Table S1 and Fig. S1). In total, 40, $552(5.1 \%)$ of the operations used minimally invasive surgery; the proportions of minimally invasive cases per year have decreased and plateaued (Additional file 1: Fig. S2).

Additional file 1: Table S2 summarises the characteristics of those in each approach group, including the type of implant used. As body mass index (BMI) was not collected in the early years of the registry (MDS v1) and data completeness for BMI improved over time, the data on this variable were not available for all patients. Metal-on-metal (MoM) hip replacements (including resurfacings) are strongly associated with higher failure rates [13] and have now largely fallen into disuse, so we focussed on the remaining 724,165 (90.6\%) non-MoM hip replacements. Finally, as only 261 of these THRs underwent minimally invasive trans-trochanteric surgery, this group was excluded, leaving 723,904 for analysis (Fig. 1). Demographics for the final 7 groups are shown in Table 1.

\section{Revision and short-term mortality}

Survival analyses were used to compare the revision rates and 90-day mortality between groups. The unit of analysis was the THR. Although 5967 had been implanted as part of a bilateral pair, these were retained in both sets of analyses as they did not necessarily have the same approach. For revision, time was measured from the date of the primary to the date of first revision, if any, censoring at the end of 2016 or at death if that occurred first. For mortality, time was measured from the date of the primary to death, censoring at 90 days or at the end of 2016 if that was earlier.

Confounders for both sets of analyses were age at primary, sex, 'risk group' (i.e. had additional indications to OA for surgery), American Society of Anesthesiologists (ASA) grade and THR fixation. Year of primary, femoral head size and BMI (values $<10$ and $>60 \mathrm{~kg} / \mathrm{m}^{2}$ were excluded as likely to be invalid) were also considered.

For mortality, other known confounders were thromboprophylaxis and anaesthetic [3]. Also included was a measure of area deprivation, the Index of Multiple 


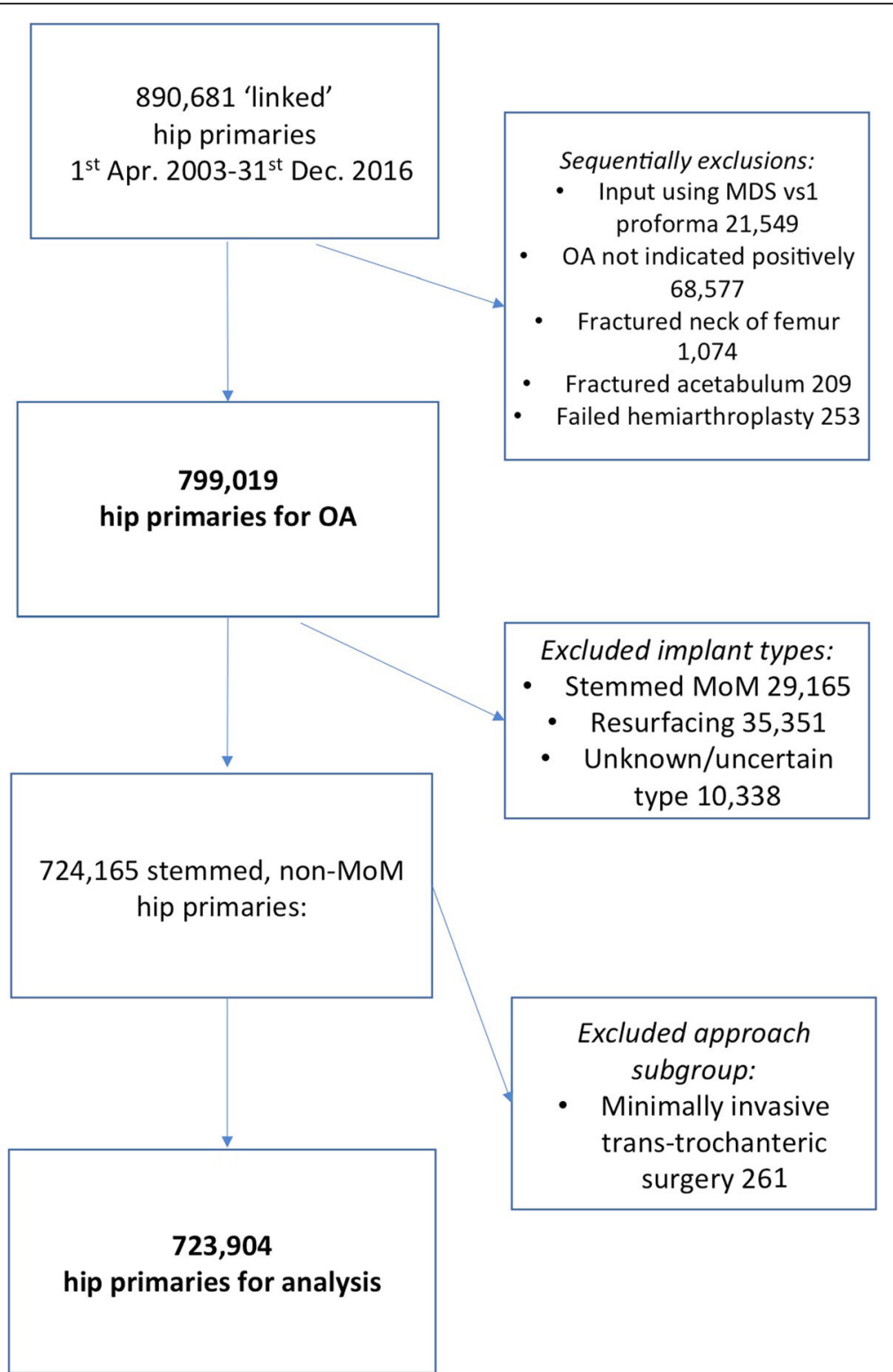

Fig. 1 Study selection criteria. Abbreviations: OA = osteoarthritis; MoM = metal-on-metal

Deprivation (IMD), obtained via linkage to Hospital Episode Statistics (HES) inpatient records (for patients with National Health Service (NHS)-funded procedures in England). The IMD is an overall ranking of the patients' 'Super Output Area' of residence, rank 1 being the most deprived area, 32,482 the least; we grouped the patients according to the quintile of their area rank.

A series of Cox 'proportional hazards' $(\mathrm{PH})$ regression models were used to compare outcomes between groups, with stratification to allow subgroups of confounder variables to have different baseline hazard rates. For revision, the analyses were supplemented with Flexible Parametric Survival Modelling (FPM) [14]. The latter gave the analyses more scope and allowed exploration of the temporal changes in the effects of confounder variables as previously utilised in NJR analyses [13].

\section{Patient-reported outcome measures (PROMs)}

The NHS PROM programme has collected PROMs for unilateral THRs in England since 1 April 2009 [15]. Patients complete validated PROM questionnaires 2 weeks before their primary operation (Q1) and approximately 6 months afterwards (Q2). Each questionnaire includes (a) the Oxford Hip Score (OHS) [16], derived from 12 questions asking about pain and mobility (over the previous 4 weeks); (b) the EuroQol-5D (EQ-5D) Health Scale [17], a visual analogue scale representing the 


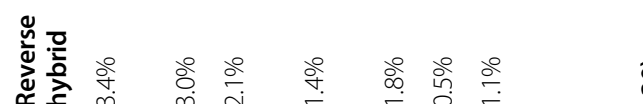

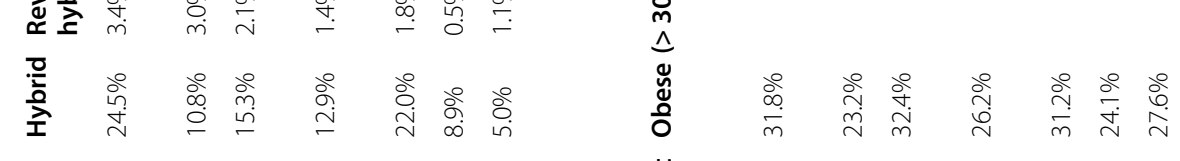

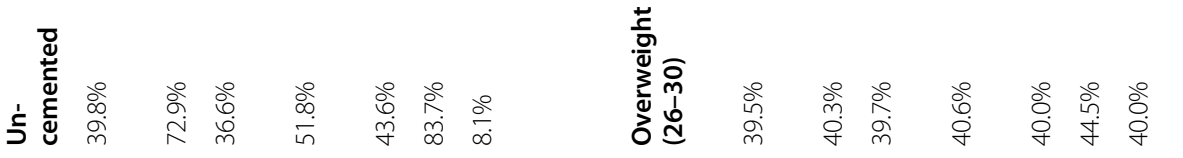

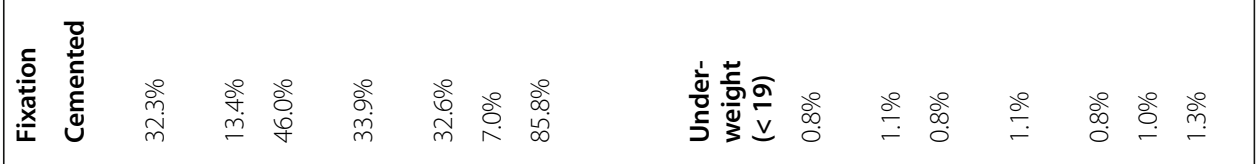

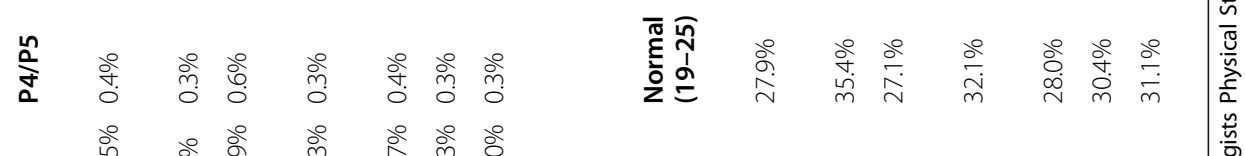

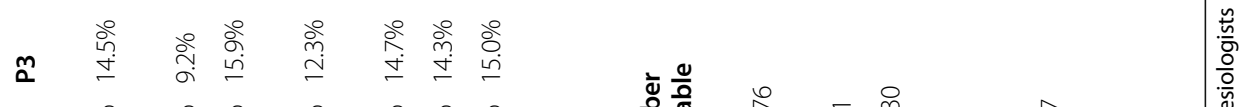

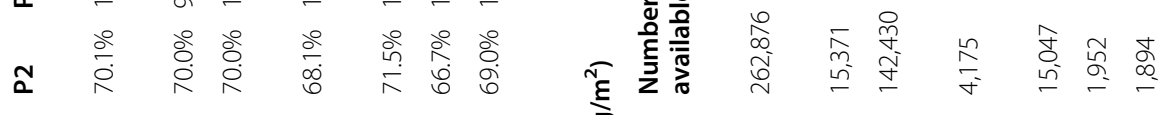

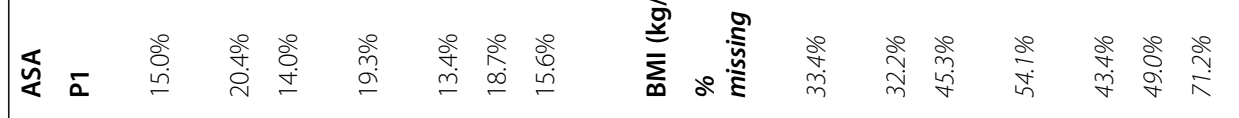

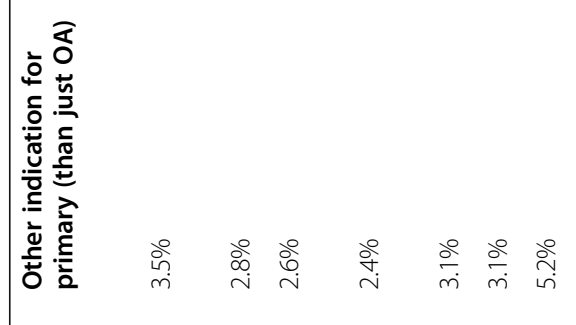

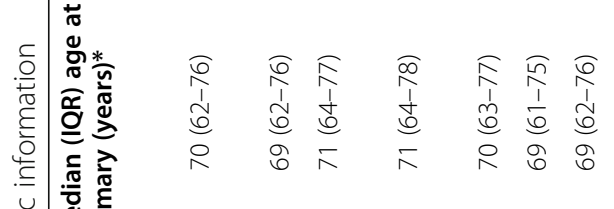

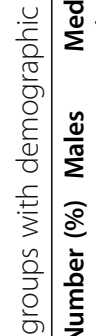

范

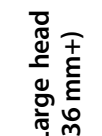

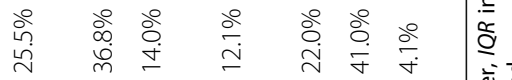

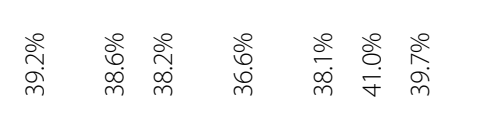

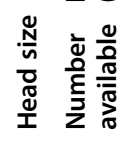

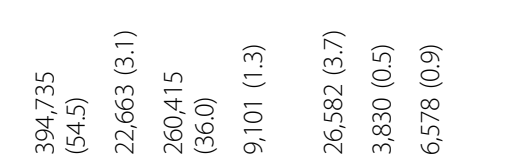

$\frac{\bar{c}}{\text { के }}$

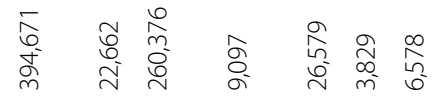

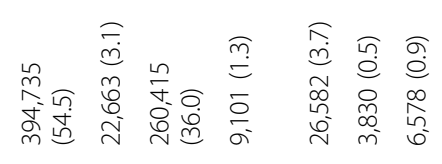

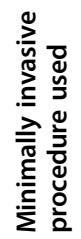

है

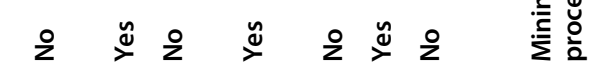

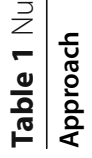

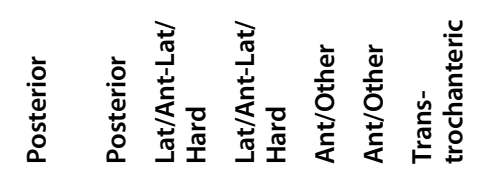

$\frac{5}{0}$
$\frac{0}{0}$
$\frac{0}{2}$
$\frac{0}{2}$

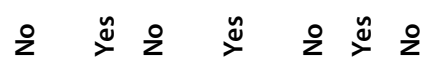

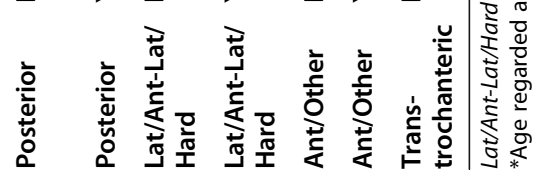


patient's health status on the day $(0=$ worst imaginable; $100=$ best imaginable) and (c) the EQ-5D-3L Index (3 response options for mobility, self-care, performing usual activities, pain/discomfort and anxiety/depression). For (c), we looked at the responses to each of the 5 questions, rather than the composite 'Index'. We also report on additional questions asked at Q2 about selfreported post-operative problems.

The NJR was linked to the PROM dataset via HES identifiers. PROM data were incomplete. Where multiple PROMs had been collected, the best 'episode matched rank' was used.

Statistical methods included regression analyses for OHS at Q2 with covariate adjustment for differences at Q1 (using fractional polynomials to linearise the relationship between Q2 and Q1), logistic regression (binary target variable) and ordered logistic (proportional odds) models for ordered categories. Non-parametric analyses (Kruskal-Wallis test) were used for complementary analyses where distributional assumptions were not met satisfactorily and followed by pairwise comparisons with Dunn's method.
Throughout, the 'conventional' posterior approach (i.e. without minimally invasive surgery) group was used as the reference; further comparisons were made between minimally invasive surgery 'yes' vs. 'no' within other main approach groups. No adjustments for multiple comparisons have been made. All statistical analyses were conducted using Stata version 14.2 (Stata/SE 14.2 software, StataCorp LLC, Texas, 1985-2015).

\section{Results \\ Revision}

A total of 12,989 (1.8\%) of 723,904 implants were revised during follow-up; 84,294 (11.6\%) died without undergoing revision. Indications for revision surgery by primary surgery approach group are summarised (Additional file 1: Table S3). Figure 2 shows the estimated cumulative percentage revised (Kaplan-Meier) up to 12 years for the 7 approach groups.

There were some differences in possible confounding factors between groups (Table 1); we adjusted for these using two approaches. The first set of analyses used a Cox $\mathrm{PH}$ regression model stratifying by 16 age/sex/risk

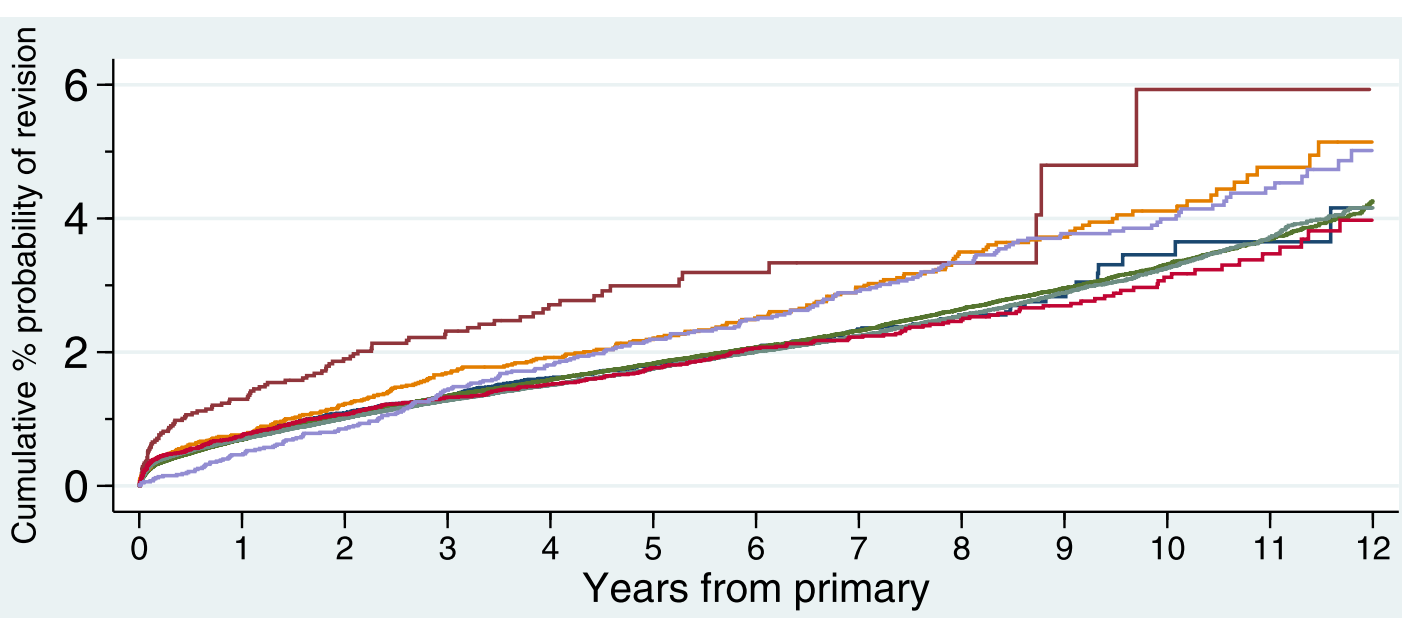

No. at risk

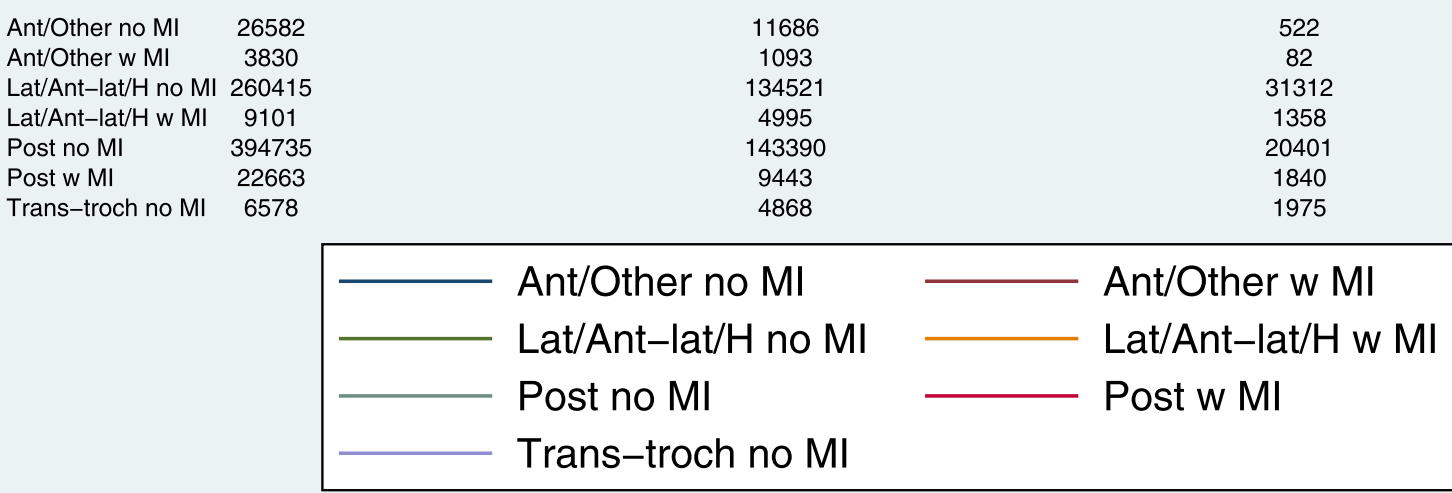

Fig. 2 Cumulative percentage revised (Kaplan-Meier) up to 12 years for the 7 surgical approach groups 
subgroups (age $<55,55-64,65-74$ and $75+$ years at primary; male vs. female; risk group, i.e. 'other indication than just OA', no vs. yes). Exploratory graphical checking suggested that the hazard rates for these subgroups were not proportional; hence, the stratification allowed their baseline hazards to differ. Table 2 (i) shows the results of these analyses. In total, 723,747 cases had complete data on age and sex and all had complete data on ASA and fixation. The middle column (Table 2 (i)) shows results with fixation and ASA as 'fixed' effects. Whilst both fixation and ASA were significant, graphical checking suggested their effects may be time-varying. However this was explored more using FPM described below. Year of primary was added to the model but was not statistically significant $(P=0.125$, likelihood ratio test). Neither was femoral head size $36 \mathrm{~mm}$ and above in those where head size was known $(P=0.256 ; n=723$, 635). Finally, BMI subgroup was added, as in the righthand side of Table 2 (i) $(P<0.001)$. The unadjusted model showed that, compared with the conventional posterior approach, there was a higher risk of revision with the conventional lateral $(P=0.009)$, minimally invasive lateral $(P<0.001)$, minimally invasive anterior $(P<$ $0.001)$ and trans-trochanteric $(P=0.004)$ approaches. Only the difference for the conventional lateral $(P<$ $0.001)$ and trans-trochanteric $(P=0.003)$ approaches remained significant after adjustment.

The second set of analyses used FPM. The baseline hazard was modelled with 4 degrees of freedom (df); timevarying effects of age (as 4 restricted cubic splines), sex and risk group were modelled with 4,1 and $1 \mathrm{df}$ respectively (Table 2 (ii)). Further adjustment was made for

Table 2 Regression models to compare approach groups for revision risk ( $n=723,747$ with complete information)

(i) Stratified Cox proportional hazards regression models, with stratification by age/sex/risk groups

\begin{tabular}{|c|c|c|c|c|}
\hline Approach & $\begin{array}{l}\text { Minimally invasive } \\
\text { procedure used }\end{array}$ & $\begin{array}{l}\text { Unadjusted Hazard } \\
\text { rate ratio }(95 \% \mathrm{Cl})\end{array}$ & $\begin{array}{l}\text { With adjustment for fixation } \\
\text { and ASA hazard rate ratio } \\
(95 \% \mathrm{Cl})\end{array}$ & $\begin{array}{l}\text { With adjustment for fixation, } \\
\text { ASA and BMI subgroup } \\
(n=443,657) \text { hazard rate } \\
\text { ratio }(95 \% \mathrm{Cl})\end{array}$ \\
\hline Posterior & No & 1 [referent] & 1 [referent] & 1 [referent] \\
\hline Posterior & Yes & $0.99[0.89-1.10] P=0.864$ & $0.92[0.83-1.02] P=0.110$ & $0.89[0.77-1.02] P=0.097$ \\
\hline Lat/Ant-Lat/Hard & No & $1.05[1.01-1.09] P=0.009$ & $1.07[1.03-1.11] P=0.001$ & $1.12[1.06-1.17] P<0.001$ \\
\hline Lat/Ant-Lat/Hard & Yes & $1.31[1.16-1.50] P<0.001$ & $1.28[1.13-1.46] P<0.001$ & $1.02[0.80-1.30] P=0.861$ \\
\hline Ant/Other & No & $1.04[0.95-1.14] P=0.431$ & $1.03[0.94-1.13] P=0.561$ & $1.01[0.88-1.15] P=0.921$ \\
\hline Ant/Other & Yes & $1.67[1.36-2.05] P<0.001$ & $1.48[1.21-1.82] P<0.001$ & $1.03[0.71-1.51] P=0.870$ \\
\hline Trans-trochanteric & No & $1.22[1.07-1.40] P=0.004$ & $1.40[1.22-1.60] P<0.001$ & $1.48[1.14-1.91] P=0.003$ \\
\hline \multicolumn{5}{|c|}{ Additional pairwise comparisons: } \\
\hline Lat/Ant-Lat/Hard & No vs. Yes & $P=0.001$ & $P=0.005$ & $P=0.475$ \\
\hline Ant/Other & No vs. Yes & $P<0.001$ & $P=0.001$ & $P=0.902$ \\
\hline \multicolumn{5}{|c|}{ (ii) FPM models, with adjustment for time-varying effects of age, sex, risk group } \\
\hline Approach & $\begin{array}{l}\text { Minimally invasive } \\
\text { procedure used }\end{array}$ & $\begin{array}{l}\text { Unadjusted Coefficient } \\
(95 \% \mathrm{Cl})\end{array}$ & \multicolumn{2}{|c|}{$\begin{array}{l}\text { With adjustment for fixation and ASA, as time-varying effects } \\
\text { Coefficient }(95 \% \mathrm{Cl})\end{array}$} \\
\hline Posterior & No & 0 [Referent] & \multicolumn{2}{|l|}{0 [Referent] } \\
\hline Posterior & Yes & $-0.006[-0.109-0.096] P=0.903$ & \multicolumn{2}{|l|}{$-0.081[-0.183-0.022] P=0.125$} \\
\hline Lat/Ant-Lat/Hard & No & $0.056[0.019-0.093] P=0.003$ & \multicolumn{2}{|l|}{$0.069[0.031-0.106] P<0.001$} \\
\hline Lat/Ant-Lat/Hard & Yes & $0.282[0.154-0.411] P<0.001$ & \multicolumn{2}{|l|}{$0.264[0.135-0.392] P<0.001$} \\
\hline Ant/Other & No & $0.031[-0.063-0.126] P=0.516$ & \multicolumn{2}{|l|}{$0.019[-0.075-0.114] P=0.688$} \\
\hline Ant/Other & Yes & $0.516[0.311-0.721] P<0.001$ & \multicolumn{2}{|l|}{$0.380[0.174-0.585] P<0.001$} \\
\hline Trans-trochanteric & No & $0.213[0.075-0.350] P=0.002$ & \multicolumn{2}{|l|}{$0.309[0.170-0.448] P<0.001$} \\
\hline \multicolumn{5}{|c|}{ Additional pairwise comparisons: } \\
\hline Lat/Ant-Lat/Hard & No vs. Yes & $P=0.001$ & \multicolumn{2}{|l|}{$P=0.003$} \\
\hline Ant/Other & No vs. Yes & $P<0.001$ & \multicolumn{2}{|l|}{$P=0.002$} \\
\hline
\end{tabular}

Lat/Ant-Lat/Hard lateral/anterolateral/Hardinge, Ant/Other anterior/other, ASA American Society of Anesthesiologists Physical Status, BMI body mass index, CI confidence interval 
fixation and ASA (here after combining P3 and P4/P5) which were also time-varying (and modelled with $\mathrm{df}=2$ and 3 respectively). We were unable to obtain convergence when we added BMI to this model. Similar to the Cox model, the unadjusted analyses showed a higher risk of revision for the conventional lateral $(P=0.003)$, minimally invasive lateral $(P<0.001)$, minimally invasive anterior $(P<0.001)$ and trans-trochanteric $(P=0.002)$ approaches. These findings persisted in the adjusted models (conventional lateral $(P<0.001)$, minimally invasive lateral $(P<$ $0.001)$, minimally invasive anterior $(P<0.001)$ and transtrochanteric $(P<0.001))$.

The FPM model demonstrated that the minimally invasive lateral and anterior approaches have higher failure rates than their corresponding conventional approaches, but with the Cox model this effect dissipates with adjustment for BMI (Table 2 (i)).

\section{PROMs}

PROMs were able to be linked to 289,296 (54\%) of the 533,477 unilateral THRs undertaken since PROM monitoring began. The cohort with PROMs was broadly similar to the remainder over this period in respect of age, sex, ASA, risk group and fixation (data not shown but available).

\section{Oxford Hip Scores (OHS)}

The pre-operative measurements $(\mathrm{Q} 1)$ were normally distributed, but the post-operative measurements $(\mathrm{Q} 2)$ were highly skewed (Additional file 1: Fig. S3) with a median score of 42 (IQR 35-46). There were differences between the groups in pre-operative Q1 scores (Additional file 1: Table S4).

Additional file 1: Table S5 shows between group comparisons of the Q2 scores. A non-parametric comparison (i) is shown because of extreme skewness. To adjust for differences in Q1, a regression model was sought. The relationship between Q2 and Q1, however, was nonlinear; fractional polynomials of Q1 were explored in conjunction with the regression and the transformation that best linearised this relationship was $\ln (1+\mathrm{Q} 1$ score). Comparisons between the mean Q2 scores with adjustment for differences in (transformed) Q1 scores are shown in (ii). The results were virtually unchanged from (i) except the difference between (3) and (4) (effect of minimally invasive surgery for 'Lat/Ant-Lat/Hard') was no longer significant. Residuals from this analysis were only approximately normal, but analysis using robust variance estimation (shown in parenthesis) left the results unchanged.

Additional file 1: Table S5 also shows the improvements in OHS between Q1 and Q2, calculated simply from 'Q2 minus Q1'. Because of the ceiling effect of the OHS (the maximum attainable score being 48), the potential to 'improve between Q1 and Q2' depends on the initial score; the right-hand side column of Additional file 1: Table S5 shows the 'potential' for improvement, calculated from ' 48 minus Q1'.

Both of these showed statistically, but not clinically [16], significant differences between the groups. We also repeated (i) and (ii) using proportional odds ordered logistic regression (not shown) with similar findings.

\section{EQ-5D-3L Health Index}

Analysis of the EQ-5D Health Scale (Visual Analogue Score) results also showed statistically, but not clinically significant differences between the subgroups (Additional file 1: Table S6).

EQ-5D-3L Health Index question responses are shown for complete pairs (Q1 and Q2) in Additional file 1: Tables S7 (a) to (e). Responses to each question took the form of 3 ordered categories as listed in these tables. In each case, logistic regression analyses were used to compare the approach groups at Q2, after first combining 2 of the 3 categories as indicated in the footnote of the table; both adjusted and unadjusted models showed differences between the approaches.

\section{Self-reported post-operative problems}

We analysed the PROM self-reported post-operative problems (Additional file 1: Table S8). There were significant differences between groups. Comparing the 2 commonest approaches, the lateral conventional approach was associated with slightly higher rates of complications than the conventional posterior approach.

\section{0-day mortality}

Figure 3 shows the cumulative mortality up to 90 days (Kaplan-Meier) for the 7 groups (logrank $P<0.001$ ).

Our previous work on mortality after hip replacement [3] had identified confounding factors, and a series of univariable analyses (data not shown, but available on request) confirmed these. Thus, in our analysis shown in Table 3, we have adjusted for these factors. Analyses included a stratification for 'risk group', as the hazard rates were not proportional over time. Age and year of primary THR were analysed as continuous variables, rather than 'grouped', and modelled using restricted cubic splines. In all models, the conventional lateral approach was associated with a higher risk of mortality than the conventional posterior approach. There were no other significant differences in mortality compared to the referent conventional posterior approach group. Similar findings were demonstrated when models were also adjusted for Charlson comorbidity subgroups, which were based on HES inpatient admissions within 5 years prior to date of primary THR operation (Table 4). 


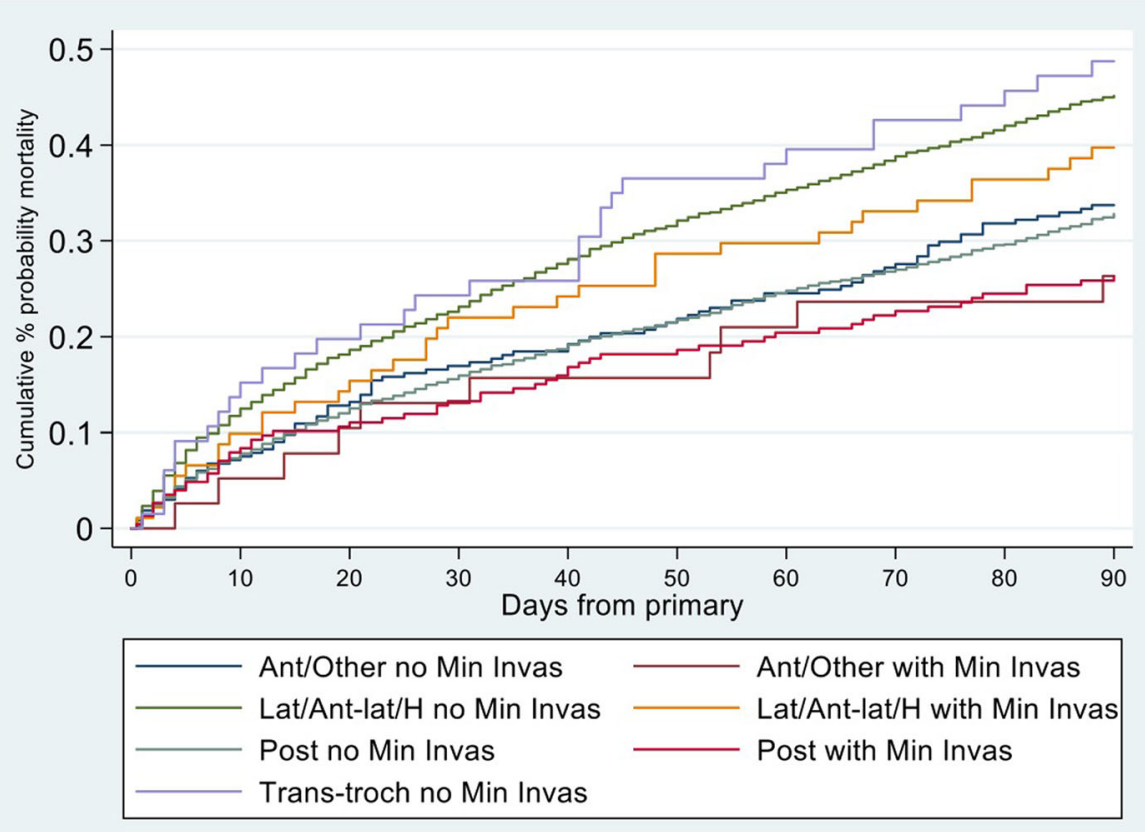

Fig. 3 Cumulative mortality up to 90 days (Kaplan-Meier) for the 7 surgical approach groups

Duplication of data by inclusion of the bilateral implants did not impact the findings; only 17 of the 2675 90-day deaths were associated with bilateral THRs.

\section{Discussion}

We have compared the 7 common surgical approaches to the hip joint used in THR by risk of revision, PROMs and 90-day mortality. In the fully adjusted Cox model, the conventional lateral and conventional transtrochanteric approaches were associated with higher risks of revision compared to the conventional posterior approach. All other approaches (including all minimally invasive approaches) were not associated with an increased revision risk. However, the fully adjusted FPM which accounts for time-varying effects showed higher risk of revision with both the conventional and minimally invasive lateral approaches and the minimally invasive anterior and the trans-trochanteric approaches.

Composite PROM scores showed statistical, but not clinically significant, differences. This is similar to findings from other registries [18]. Self-reported specific complications such as bleeding and reoperation were higher with the conventional lateral approach than the conventional posterior approach, but again, there were no other consistent meaningful differences found. Ninety-day mortality was higher in the conventional lateral approach group when compared with the conventional posterior approach, but there were no other significant differences.
Registry data is observational and thus causation cannot be attributed. However, the associations shown here are consistent even with thorough adjustment for confounders. Some BMI data is missing as this was not collected in the early years of the NJR. Previously when analysing this dataset, we have used multiple imputation for BMI data, but this did not affect the results [3], suggesting data was missing at random. Any missing revisions would also be expected to be missing at random when analysing by primary approach. Registry data is generalisable as it encompasses the entire population and is thus less susceptible to selection and reporting bias. Some iterations of the NJR MDS and reporting of the data from those versions of the MDS did not specify 'anterior' as a separate category of approach, but included it with 'other'; therefore, these groups were combined. It is possible that some of the cases defined as 'other' were not anterior and did not fit into any of the other approach groups defined in this analysis or their minimally invasive variants, but we believe the number of such cases would be small given the limited options for other hip approaches.

Furthermore, limited information is collected in the NJR regarding what specific minimally invasive surgical techniques were used, other than the use of a small skin incision, with these approaches only accounting for a small subgroup (5.1\%) of the cohort. Although we recognise further research is needed into defining and categorising minimally invasive approaches, we considered it important to include these patients given a conscious 
Table 3 Cox 'proportional hazards' regression model to compare 90-day mortality between the 7 approach subgroups

\begin{tabular}{|c|c|c|c|c|c|}
\hline Approach & $\begin{array}{l}\text { Minimally } \\
\text { invasive } \\
\text { procedure } \\
\text { used }\end{array}$ & $\begin{array}{l}\text { Number for } \\
\text { analysis }\end{array}$ & $\begin{array}{l}\text { (i) Unadjusted model } \\
\text { ( } n=723,747 ; 2673 \\
\text { deaths) hazard rate } \\
\text { ratio }[95 \% \mathrm{Cl}]\end{array}$ & $\begin{array}{l}\text { (ii) With covariate } \\
\text { adjustment for sex, age, } \\
\text { ASA and year of primary, } \\
\text { stratified by 'risk group' } \\
\text { ( } n=723,747 ; 2673 \text { deaths) } \\
\text { hazard rate ratio }[95 \% \mathrm{Cl}]\end{array}$ & $\begin{array}{l}\text { (iii) With covariate } \\
\text { adjustment for sex, age, } \\
\text { ASA, year of primary and } \\
\text { fixation, stratified by 'risk } \\
\text { group' ( } n=723,747 ; 2673 \\
\text { deaths) hazard rate ratio } \\
\text { [95\%Cl] }\end{array}$ \\
\hline Posterior & No & 394,655 & 1 [referent] & 1 [referent] & 1 [referent] \\
\hline Posterior & Yes & 22,655 & $0.80[0.62-1.04] P=0.101$ & $0.88[0.68-1.14] P=0.344$ & $0.90[0.69-1.17] P=0.447$ \\
\hline Lat/Ant-Lat/Hard & No & 260,353 & $1.38[1.27-1.49] P<0.001$ & $1.14[1.05-1.24] P=0.002$ & 1.14 [1.05-1.23] P = 0.002 \\
\hline Lat/Ant-Lat/Hard & Yes & 9099 & $1.21[0.87-1.69] P=0.252$ & $1.02[0.73-1.43] P=0.896$ & $1.03[0.74-1.44] P=0.847$ \\
\hline Ant/Other & No & 26,578 & $1.03[0.83-1.28] P=0.793$ & $0.96[0.77-1.19] P=0.703$ & $0.96[0.77-1.19] P=0.715$ \\
\hline Ant/Other & Yes & 3829 & $0.80[0.43-1.50] P=0.493$ & $0.88[0.47-1.65] P=0.697$ & $0.91[0.49-1.71] P=0.780$ \\
\hline Trans-trochanteric & No & 6578 & $1.49[1.05-2.11] P=0.026$ & $1.19[0.83-1.69] P=0.342$ & $1.16[0.81-1.65] P=0.412$ \\
\hline \multicolumn{6}{|c|}{ Additional pairwise comparisons: } \\
\hline Lat/Ant-Lat/Hard & No vs. Yes & & $P=0.452$ & $P=0.517$ & $P=0.573$ \\
\hline Ant/Other & No vs. Yes & & $P=0.460$ & $P=0.807$ & $P=0.884$ \\
\hline Approach & $\begin{array}{l}\text { Minimally } \\
\text { invasive } \\
\text { procedure } \\
\text { used }\end{array}$ & \multicolumn{2}{|c|}{$\begin{array}{l}\text { (iv) With covariate } \\
\text { adjustment for sex, age, } \\
\text { ASA, year of primary, } \\
\text { fixation, mechanical and } \\
\text { chemical thromboprophylaxis } \\
\text { and anaesthetic group, } \\
\text { stratified by 'risk group' } \\
\text { ( } n=713,994 \text { with complete } \\
\text { information; } 2621 \text { deaths) } \\
\text { hazard rate ratio }[95 \% \mathrm{Cl}]\end{array}$} & $\begin{array}{l}\text { (v) With covariate } \\
\text { adjustment for sex, age, } \\
\text { ASA, year of primary, } \\
\text { fixation, mechanical and } \\
\text { chemical thromboprophylaxis, } \\
\text { anaesthetic group and quintile } \\
\text { of area deprivation, stratified } \\
\text { by 'risk group' ( } n=572,719 \\
\text { with complete information; } \\
2192 \text { deaths) hazard rate } \\
\text { ratio }[95 \% \mathrm{Cl}]\end{array}$ & $\begin{array}{l}\text { (vi) With covariate } \\
\text { adjustment for sex, age, } \\
\text { ASA, year of primary, } \\
\text { fixation, mechanical and } \\
\text { chemical thromboprophylaxis, } \\
\text { anaesthetic group, quintile } \\
\text { of area deprivation and BMI } \\
\text { subgroup, stratified by 'risk } \\
\text { group' ( } n=359,883 \text { with } \\
\text { complete information; } 1148 \\
\text { deaths) hazard rate ratio } \\
{[95 \% \mathrm{Cl}]}\end{array}$ \\
\hline Posterior & No & \multicolumn{2}{|l|}{1 [referent] } & 1 [referent] & 1 [referent] \\
\hline Posterior & Yes & \multicolumn{2}{|c|}{$0.91[0.70-1.18] P=0.475$} & $0.93[0.68-1.27] P=0.644$ & $0.87[0.57-1.34] P=0.525$ \\
\hline Lat/Ant-Lat/Hard & No & \multicolumn{2}{|c|}{$1.16[1.06-1.26] P=0.001$} & $1.11[1.01-1.21] P=0.027$ & $1.15[1.01-1.30] P=0.029$ \\
\hline Lat/Ant-Lat/Hard & Yes & \multicolumn{2}{|c|}{$0.91[0.63-1.31] P=0.605$} & $0.87[0.58-1.31] P=0.512$ & $0.80[0.41-1.55] P=0.507$ \\
\hline Ant/Other & No & \multicolumn{2}{|c|}{$0.96[0.78-1.20] P=0.732$} & $0.94[0.75-1.19] P=0.620$ & $0.89[0.63-1.26] P=0.509$ \\
\hline Ant/Other & Yes & \multicolumn{2}{|c|}{$0.92[0.49-1.71] P=0.787$} & $1.23[0.61-2.47] P=0.563$ & $1.01[0.32-3.15] P=0.986$ \\
\hline Trans-trochanteric & No & \multicolumn{2}{|c|}{$1.16[0.81-1.67] P=0.409$} & $1.12[0.75-1.68] P=0.571$ & $1.12[0.52-2.41] P=0.771$ \\
\hline \multicolumn{6}{|c|}{ Additional pairwise comparisons: } \\
\hline Lat/Ant-Lat/Hard & No vs Yes & \multicolumn{2}{|l|}{$P=0.195$} & $P=0.250$ & $P=0.283$ \\
\hline Ant/Other & No vs Yes & \multicolumn{2}{|l|}{$P=0.885$} & $P=0.447$ & $P=0.833$ \\
\hline
\end{tabular}

Lat/Ant-Lat/Hard lateral/anterolateral/Hardinge, Ant/Other anterior/other, ASA American Society of Anesthesiologists Physical Status, BMI body mass index, Cl confidence interval

effort was made by the surgeon to minimise the incision length, which may influence the technical performance and/or outcome of the THR.

A number of small randomised controlled trials (RCTs) have compared the effect of two THR approaches; however, these have limitations. Cheng et al. $(n=72)$ observed that the anterior approach had similar results at 12 weeks to the posterior approach in terms of complications, patient-reported outcomes and gait, aside from neuropraxia which was more common following the anterior approach [11]. Taunton et al. $(n=101)$ found that although there were some early benefits of the anterior approach (e.g. earlier discontinuation of walking aids), it was similar to the minimally invasive posterior approach at 1 year for PROMs, complications and radiographic parameters [19]. Two trials comparing the lateral with the posterior approach showed the posterior approach had greater improvement in muscle strength at 1 year $(n=47)$ [20], and fewer dislocations at an average 3-year follow-up $(n=196)$ [21]. A recent 
Table 4 Cox 'proportional hazards' regression model to compare 90-day mortality between the 7 approach subgroups. Models from Table 3 were also adjusted for Charlson comorbidity subgroups, which were based on HES inpatient admissions within 5 years prior to date of primary THR operation

\begin{tabular}{|c|c|c|c|c|}
\hline Approach & $\begin{array}{l}\text { Minimally invasive } \\
\text { procedure used }\end{array}$ & $\begin{array}{l}\text { (i) With covariate adjustment } \\
\text { for sex, age, ASA, year of } \\
\text { primary, fixation, mechanical } \\
\text { and chemical thromboprophylaxis, } \\
\text { anaesthetic group and Charlson } \\
\text { comorbidity subgroups, stratified } \\
\text { by 'risk group' ( } n=578,624 \text { with } \\
\text { complete information; } 2205 \\
\text { deaths) hazard rate ratio }[95 \% \mathrm{Cl}]\end{array}$ & $\begin{array}{l}\text { (ii) With covariate adjustment } \\
\text { for sex, age, ASA, year of } \\
\text { primary, fixation, mechanical } \\
\text { and chemical thromboprophylaxis, } \\
\text { anaesthetic group, Charlson } \\
\text { comorbidity subgroups and } \\
\text { quintile of area deprivation, } \\
\text { stratified by 'risk group' } \\
\text { ( } n=572,719 \text { with complete } \\
\text { information; } 2192 \text { deaths) } \\
\text { hazard rate ratio }[95 \% \mathrm{Cl}]\end{array}$ & $\begin{array}{l}\text { (iii) With covariate adjustment } \\
\text { for sex, age, ASA, year of primary, } \\
\text { fixation, mechanical and chemical } \\
\text { thromboprophylaxis, anaesthetic } \\
\text { group, Charlson comorbidity } \\
\text { subgroups, quintile of area } \\
\text { deprivation and BMl subgroup, } \\
\text { stratified by 'risk group' } \\
\text { ( } n=359,883 \text { with complete } \\
\text { information; } 1148 \text { deaths) hazard } \\
\text { rate ratio }[95 \% \mathrm{Cl}]\end{array}$ \\
\hline Posterior & No & 1 [referent] & 1 [referent] & 1 [referent] \\
\hline Posterior & Yes & $0.94[0.69-1.28] P=0.705$ & $0.94[0.69-1.28] P=0.678$ & $0.86[0.56-1.33] P=0.499$ \\
\hline $\begin{array}{l}\text { Lat/Ant-Lat/ } \\
\text { Hard }\end{array}$ & No & $1.13[1.04-1.24] P=0.007$ & $1.12[1.02-1.23] P=0.013$ & $1.16[1.02-1.31] P=0.022$ \\
\hline $\begin{array}{l}\text { Lat/Ant-Lat/ } \\
\text { Hard }\end{array}$ & Yes & $0.89[0.59-1.34] P=0.579$ & $0.88[0.59-1.33] P=0.555$ & $0.81[0.42-1.57] P=0.539$ \\
\hline Ant/Other & No & $0.96[0.76-1.21] P=0.726$ & $0.96[0.76-1.21] P=0.706$ & $0.90[0.64-1.27] P=0.549$ \\
\hline Ant/Other & Yes & $1.29[0.64-2.59] P=0.473$ & $1.32[0.66-2.65] P=0.435$ & $1.10[0.35-3.42] P=0.872$ \\
\hline $\begin{array}{l}\text { Trans- } \\
\text { trochanteric }\end{array}$ & No & $1.15[0.77-1.73] P=0.486$ & $1.15[0.77-1.71] P=0.506$ & $1.16[0.54-2.50] P=0.701$ \\
\hline \multicolumn{5}{|c|}{ Additional pairwise comparisons: } \\
\hline $\begin{array}{l}\text { Lat/Ant- } \\
\text { Lat/Hard }\end{array}$ & No vs Yes & $P=0.247$ & $P=0.253$ & $P=0.296$ \\
\hline Ant/Other & No vs Yes & $P=0.425$ & $P=0.386$ & $P=0.741$ \\
\hline
\end{tabular}

Lat/Ant-Lat/Hard lateral/anterolateral/Hardinge, Ant/Other anterior/other, ASA American Society of Anesthesiologists Physical Status, BMI body mass index, Cl confidence interval

*There were no 90-day deaths for human immunodeficiency virus so this was not included in the analysis

RCT $(n=164)$ found the lateral approach was associated with more abductor muscle weakness and worse PROMs, but the anterior approach had more nerve injuries [22]. A systematic review, including 12 RCTs, reported similar risks of dislocation, nerve injury, infection and venous thromboembolism between the posterior approach and the minimally invasive posterior approach [10].

The RCTs comparing surgical approach are not large enough to compare less common but important events such as revision and mortality rates. We observed that the conventional lateral approach was associated with higher revision and mortality rates than the conventional posterior approach. Previous studies have also observed higher revision rates (for all causes apart from dislocation) [23] and higher mortality rates [3] with the lateral compared to the posterior approach. The posterior approach is a more muscle-sparing approach compared with the lateral approach and is associated with less bleeding [8]. Problems seen more commonly following the anterolateral approach include nerve injury [8], reduced muscle strength [9] and limping [10]. These problems invariably influence patient mobility, especially in the early post-operative phase, when the mortality risk is higher. Previous work on mortality after THR showed lower all-cause mortality, and mortality from respiratory issues with the posterior approach; this finding is most likely related to improved mobility after surgery [24]. It is therefore plausible that a combination of these factors contribute to the higher revision and mortality rates observed for the lateral approach compared to the posterior approach.

The conventional lateral approach $(36.0 \%)$ is the second most popular approach and is currently used annually in over 20,000 primary THRs in the NJR. This approach was associated with worse outcomes in all measures than the commonest approach, the conventional posterior (54.5\%). Therefore, the data presented here does not support its continued use over alternative approaches. Although the conventional transtrochanteric approach was associated with higher revision rates (compared with the posterior approach), it is acknowledged that this approach is rarely used now, and when it is used it is usually for more complex cases (such as hip ankylosis, proximal femoral deformities and acetabular protrusio), which may explain the inferior outcomes observed here with the conventional transtrochanteric approach. By contrast, the posterior approach is common, extensile and associated with good outcomes in comparison to other approaches. Therefore, 
we recommend the posterior approach should be considered the current standard surgical approach for THR. It would be difficult and perhaps unwise to attempt conversion of experienced surgeons to an approach with which they may be unfamiliar. However, surgeons in training should be taught alternative approaches to the lateral associated with better outcomes, like the posterior approach. The data does support continued use of minimally invasive approaches, with acceptable mortality and PROM outcomes, although minimally invasive lateral and anterior approaches may be associated with higher revision rates than their corresponding conventional approaches.

\section{Conclusion}

The lateral approach was associated with worse outcomes, including more deaths and more revisions, than the posterior approach for primary THR. We thus recommend that new surgeons do not routinely use the lateral approach for THR. The conventional posterior approach is common and associated with at least as good outcomes as other less common approaches; therefore, we recommend the posterior approach should be considered the current standard approach for THR and should be used when training future surgeons. As minimally invasive posterior approaches and the conventional anterior approach had outcomes in our observational data similar to the conventional posterior approach in all domains, these should be assessed further in randomised controlled trials and compared with the conventional posterior approach.

\section{Supplementary information}

Supplementary information accompanies this paper at https://doi.org/10. 1186/s12916-020-01672-0.

\footnotetext{
Additional file 1. Summary information including temporal trends of clinical practice, detailed demographics of the cohort divided by surgical approach, indications for revision surgery, and detailed analyses of patient reported outcome measures. Fig. S1. Numbers of primaries using each surgical approach in each year. Fig. S2. (a) Numbers of primaries using minimally invasive surgery (No vs. Yes), by year of primary, (b) Percentage of primaries using minimally invasive surgery, by year of primary. Fig. S3. Distribution of post-operative (Q2) OHS available for 237,660 hips, with a Normal distribution superimposed (OHS score range 0 to 48 with 48 being the best possible score). Table S1. Surgical approach by year of primary. Table S2. Numbers in the approach subgroups together with some demographic information. Table $\mathbf{S 3 .}$ Indications for revision surgery by surgical approach used at the primary procedure. Table S4. Comparison of pre-operative (Q1) PROMS Oxford Hip Scores (OHS) between the approach subgroups. Table S5. Comparison of PROMS OHS scores between the approach subgroups. Table S6. Comparison of the EQ-5D Health Scale (Visual Analogue Score) between the approach subgroups. Table S7. Comparison between the approach subgroups in respect of the responses to the 5 component questions of the PROMs EQ-5D Health Index: (a) Mobility, (b) Self care, (c) Usual activity, (d) Pain/discomfort, (e) Anxiety/depression. Table S8. Other PROMS comparison of patient self-report post-operative $(\mathrm{Q} 2)$ problems between the approach subgroups.
}

\section{Abbreviations}

ASA: American Society of Anesthesiologists; BMI: Body mass index; Cl: Confidence intervals; df: Degrees of freedom; EQ-5D: EuroQol-5D; FPM: Flexible Parametric Survival Modelling; HRR: Hazard rate ratio; HES: Hospital Episode Statistics; IMD: Index of Multiple Deprivation; IQR: Interquartile range; MoM: Metal-on-metal; MDS: Minimum data set; NHS: National Health Service; NJR: National Joint Registry; OA: Osteoarthritis; OHS: Oxford Hip Score; PROM: Patient-reported outcome measure; PH: Proportional hazards; RCT: Randomised controlled trial; THR: Total hip replacement

\section{Acknowledgements}

This study was supported by funding from Healthcare Quality Improvement Partnership and the National Joint Registry. Posts of authors of this work are partly funded by a grant from the National Joint Registry to conduct statistical analysis for the National Joint Registry.

This study was also supported by the NIHR Biomedical Research Centre at University Hospitals Bristol NHS Foundation Trust and the University of Bristol. The views expressed in this publication are those of the author(s) and not necessarily those of the NHS, the National Institute for Health Research or the Department of Health and Social Care.

We thank the patients and staff of all the hospitals who have contributed data to the National Joint Registry. We are grateful to the Healthcare Quality Improvement Partnership, the National Joint Registry Steering Committee, and staff at the National Joint Registry for facilitating this work. The views expressed represent those of the authors and do not necessarily reflect those of the National Joint Registry Steering Committee or Healthcare Quality Improvement Partnership, who do not vouch for how the information is presented.

\section{Authors' contributions}

AWB, LPH and MRW conceived and designed the study. LPH undertook all analysis and had access to all the data. GSM undertook the literature search. AWB, LPH, GSM, MR and MRW critically inputted into final design of the study, interpreted the data and co-wrote the manuscript. AWB is the guarantor and attests on behalf of the authors that the manuscript is a true and transparent reflection of the study without omissions. All authors read and approved the final manuscript.

\section{Funding}

This study was supported by funding from Healthcare Quality Improvement Partnership, National Joint Registry and the NIHR Biomedical Research Centre at University Hospitals Bristol NHS Foundation Trust and the University of Bristol.

\section{Availability of data and materials}

Access to data is available from the National Joint Registry for England, Wales, Northern Ireland and the Isle of Man, but restrictions apply to the availability of these data, which were used under licence for the current study, and so are not publicly available. Data access applications can be made to the National Joint Registry Research Committee. Access to linked HES and PROM data is available through data applications to NHS Digital.

\section{Ethics approval and consent to participate}

Our protocol was approved by the National Joint Registry Research Subcommittee. NHS Health Research Authority advise that secondary uses of anonymised data for audit, research and quality improvement do not require approval by a research ethics committee. With support under Section 251 of the NHS Act 2006, the Ethics and Confidentiality Committee (ECC), (now the Health Research Authority Confidentiality Advisory Group) allows the NJR to collect patient data where consent is indicated as 'Not Recorded'.

\section{Consent for publication}

Before Personal Data and Sensitive Personal Data is recorded, express written patient consent is provided. The NJR records patient consent as either 'Yes', 'No' or 'Not Recorded'.

\section{Competing interests}

AWB is a principal investigator on a grant funded by Stryker investigating the outcome of a total knee replacement manufactured by Stryker. GSM has received financial support for other research work from Arthritis Research UK, 
The Orthopaedics Trust, The Royal College of Surgeons of England and The Royal Orthopaedic Hospital Hip Research and Education Charitable Fund. GSM has also received personal fees for undertaking medicolegal work for Leigh Day. MRR has received grant funding or lecture fees from the Health Foundation, Stryker, Zimmer Biomet, Heraeus Medical, $3 \mathrm{M}$ healthcare, Vifor Pharma and Schuelke. MRW is a co-applicant on a grant funded by Stryker investigating the outcome of a total knee replacement manufactured by Stryker.

\section{Author details}

Musculoskeletal Research Unit, Translational Health Sciences, Bristol Medical School, 1st Floor Learning \& Research Building, Southmead Hospital, Bristol BS10 5NB, UK. ${ }^{2}$ National Institute for Health Research Bristol Biomedical Research Centre, University Hospitals Bristol NHS Foundation Trust and University of Bristol, Bristol, UK. ${ }^{3}$ Northumbria Healthcare NHS Foundation Trust, Department of Trauma and Orthopaedics, Wansbeck General Hospital, Woodhorn Lane, Ashington NE63 9JJ, UK.

Received: 19 March 2020 Accepted: 19 June 2020

Published online: 06 August 2020

\section{References}

1. Evans JT, Evans JP, Walker RW, Blom AW, Whitehouse MR, Sayers A. How long does a hip replacement last? A systematic review and meta-analysis of case series and national registry reports with more than 15 years of followup. Lancet. 2019;393(10172):647-54.

2. Lenguerrand E, Wylde V, Gooberman-Hill R, Sayers A, Brunton L, Beswick $A D$, Dieppe $P$, Blom AW. Trajectories of pain and function after primary hip and knee arthroplasty: the ADAPT cohort study. PLoS One. 2016;11(2): e0149306.

3. Hunt LP, Ben-Shlomo Y, Clark EM, Dieppe P, Judge A, MacGregor AJ, Tobias $\mathrm{JH}$, Vernon K, Blom AW. National Joint Registry for England W, Northern I. 90-day mortality after 409,096 total hip replacements for osteoarthritis, from the National Joint Registry for England and Wales: a retrospective analysis. Lancet. 2013:382(9898):1097-104.

4. Deere KC, Whitehouse MR, Porter M, Blom AW, Sayers A. Assessing the noninferiority of prosthesis constructs used in hip replacement using data from the National Joint Registry of England, Wales, Northern Ireland and the Isle of Man: a benchmarking study. BMJ Open. 2019;9(4):e026685.

5. Anderson DR, Dunbar M, Murnaghan J, Kahn SR, Gross P, Forsythe M, Pelet S, Fisher W, Belzile E, Dolan S, Crowther M, Bohm E, MacDonald SJ, Gofton W, Kim P, Zukor D, Pleasance S, Andreou P, Doucette S, Theriault C, Abianui A, Carrier M, Kovacs MJ, Rodger MA, Coyle D, Wells PS, Vendittoli PA. Aspirin or rivaroxaban for VTE prophylaxis after hip or knee arthroplasty. N Engl J Med. 2018:378(8):699-707.

6. Meermans G, Konan S, Das R, Volpin A, Haddad FS. The direct anterior approach in total hip arthroplasty: a systematic review of the literature. Bone Joint J. 2017;99-B(6):732-40.

7. Migliorini F, Biagini M, Rath B, Meisen N, Tingart M, Eschweiler J. Total hip arthroplasty: minimally invasive surgery or not? Meta-analysis of clinical trials. Int Orthop. 2019;43(7):1573-82.

8. Weale $A E$, Newman P, Ferguson IT, Bannister GC. Nerve injury after posterior and direct lateral approaches for hip replacement. A clinical and electrophysiological study. J Bone Joint Surg Br. 1996;78(6):899-902.

9. Winther SB, Husby VS, Foss OA, Wik TS, Svenningsen S, Engdal M, Haugan K, Husby OS. Muscular strength after total hip arthroplasty. A prospective comparison of 3 surgical approaches. Acta Orthop. 2016;87(1):22-8.

10. Berstock JR, Blom AW, Beswick AD. A systematic review and meta-analysis of complications following the posterior and lateral surgical approaches to total hip arthroplasty. Ann R Coll Surg Engl. 2015;97(1):11-6.

11. Cheng TE, Wallis JA, Taylor NF, Holden CT, Marks P, Smith CL, Armstrong MS, Singh PJ. A prospective randomized clinical trial in total hip arthroplasty-comparing early results between the direct anterior approach and the posterior approach. J Arthroplast. 2017;32(3):883-90.

12. National Joint Registry (NJR) for England, Wales, Northern Ireland and the Isle of Man 15th Annual Report. 2018:http://www.njrreports.org.uk/Portals/0/ PDFdownloads/NJR 15th 20 Annual 20Report 2018.pdf.

13. Hunt LP, Whitehouse MR, Beswick A, Porter ML, Howard P, Blom AW. Implications of introducing new technology: comparative survivorship modeling of metal-on-metal hip replacements and contemporary alternatives in the National Joint Registry. J Bone Joint Surg Am. 2018; 100(3):189-96.

14. Royston P, Lambert PC. Flexible parametric survival analysis using Stata: beyond the Cox model. Stata Press. 2011.

15. NHS Digital. Patient Reported Outcome Measures (PROMs) - NHS Digital digital.nhs.uk. 2019. Available from: https://digital.nhs.uk/data-andinformation/data-tools-and-services/data-services/patient-reported-outcomemeasures-proms.

16. Murray DW, Fitzpatrick R, Rogers K, Pandit H, Beard DJ, Carr AJ, Dawson J. The use of the Oxford hip and knee scores. J Bone Joint Surg Br. 2007;89(8): 1010-4.

17. EuroQol G. EuroQol--a new facility for the measurement of health-related quality of life. Health Policy. 1990;16(3):199-208.

18. Lindgren JV, Wretenberg P, Karrholm J, Garellick G, Rolfson O. Patientreported outcome is influenced by surgical approach in total hip replacement: a study of the Swedish Hip Arthroplasty Register including 42,233 patients. Bone Joint J. 2014;96-B(5):590-6.

19. Taunton MJ, Trousdale RT, Sierra RJ, Kaufman K, Pagnano MW. John Charnley award: randomized clinical trial of direct anterior and miniposterior approach THA: which provides better functional recovery? Clin Orthop Relat Res. 2018;476(2):216-29.

20. Rosenlund S, Broeng L, Overgaard S, Jensen C, Holsgaard-Larsen A. The efficacy of modified direct lateral versus posterior approach on gait function and hip muscle strength after primary total hip arthroplasty at 12 months follow-up. An explorative randomised controlled trial. Clin Biomech (Bristol, Avon). 2016;39:91-9.

21. Ji HM, Kim KC, Lee YK, Ha YC, Koo KH. Dislocation after total hip arthroplasty: a randomized clinical trial of a posterior approach and a modified lateral approach. J Arthroplast. 2012;27(3):378-85.

22. Mjaaland KE, Kivle K, Svenningsen S, Nordsletten L. Do postoperative results differ in a randomized trial between a direct anterior and a direct lateral approach in THA? Clin Orthop Relat Res. 2019;477(1):145-55.

23. Zijlstra WP, De Hartog B, Van Steenbergen LN, Scheurs BW, Nelissen R. Effect of femoral head size and surgical approach on risk of revision for dislocation after total hip arthroplasty. Acta Orthop. 2017;88(4):395-401.

24. Hunt LP, Whitehouse MR, Howard PW, Ben-Shlomo Y, Blom AW. Using long term mortality to determine which perioperative risk factors of mortality following hip and knee replacement may be causal. Sci Rep. 2018;8(1):15026.

\section{Publisher's Note}

Springer Nature remains neutral with regard to jurisdictional claims in published maps and institutional affiliations.

Ready to submit your research? Choose BMC and benefit from

- fast, convenient online submission

- thorough peer review by experienced researchers in your field

- rapid publication on acceptance

- support for research data, including large and complex data types

- gold Open Access which fosters wider collaboration and increased citations

- maximum visibility for your research: over $100 \mathrm{M}$ website views per year

At $\mathrm{BMC}$, research is always in progress.

Learn more biomedcentral.com/submissions 